\title{
AORISTO INGRESIVO EN GRIEGO ANTIGUO
}

\section{Rafael Martínez Vázquez}

Del aoristo ingresivo griego existen varias explicaciones fundamentales, pero de ninguna de ellas se puede decir que sea la doctrina común, aceptada siquiera por la mayoría de los estudiosos de la lengua clásica. Es llamativa la diferencia existente entre dos de ellas. Una desarrolla la tesis de que el aoristo griego tiene un valor confectivo en todos sus usos: el ingresivo sería una variante de ese valor. Otra postula que el ingresivo y otros usos son irreductibles a un valor único, de modo que el ingresivo sería un uso especial del aoristo, tema capaz de expresar más de un valor gramatical. Ambas tesis se defienden desde la perspectiva de un análisis del paradigma de morfemas aspectuales y su realización en lexemas dados. Es difícil, desde esa perspectiva, optar por una solución o por la otra, a falta de recursos formales con los que argumentar. Mas desde la perspectiva de las realizaciones o variantes combinatorias de uno y otro en la predicación y su realización en el texto puede acaso superarse esta aporía, ya que la ambigüedad del morfema, del lexema, del lexema con morfema, suele resolverse como sentido concreto en el nivel de la predicación.

En su Gr. Grammatik SCHWYZER ${ }^{1}$ sostiene que el tema de aoristo tiene el valor constante de indicar el contenido verbal incluido su término: valor confectivo. El empleo conocido habitualmente como aoristo ingresivo, que él denomina metaptotischer Aorist,

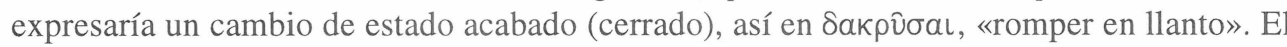
estado precedente, aquí el no-llorar, cae fuera del ámbito denotativo del verbo en cuestión,

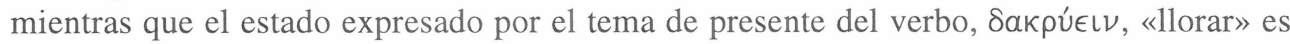
consecuencia del proceso aorístico (SCHWYZER 1950:261). SCHWYZER se hace eco de una larga tradición, represenatada por filólogos y gramáticos, sobre todo alemanes, en cuyas obras puede leerse, a lo largo de centenares de páginas, una tesis que recurre hasta la saciedad: el único valor propio del tema de aoristo es la indicación de la acción acabada, completa $^{2}$. Pese a tanto empeño, aparentemente no dieron con una explicación convincente del aoristo ingresivo, que haya trascendido a nuestros tiempos. SCHWYZER se limita a apuntar que el hecho de que el aoristo ingresivo (incoativo) es también confectivo, debería en adelante demostrarse con claridad (1950:261, n.1). Y es que sus predecesores habían

\footnotetext{
${ }^{1}$ SCHWYZER, E. - DEBRUNNER, A. (1950), Griechische Grammatik II, München, Beck, 1950.

2 Acaso los más significativos sean MELTZER, H., "Zur Lehre von den Aktionen bes. im Griechischen", If 1 , 1904-5, 187-277; HARTMANN, F., "Aorist und Imperfektum", KZ 48, 1918, 1-47 y 49, 1919, 1-73.
} 
desenfocado la cuestión al poner todo su empeño en demostrar que el sentido ingresivo no era ajeno al tema de presente. Los escasos ejemplos que aducen no prueban la existencia de un sentido ingresivo en dicho tema y mucho menos, como pretende HARTMANN, que el sentido ingresivo del aoristo se explique a partir del "verdadero" sentido ingresivo del tema

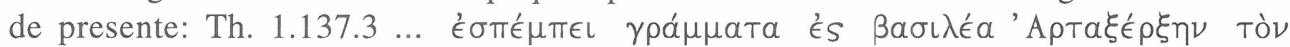

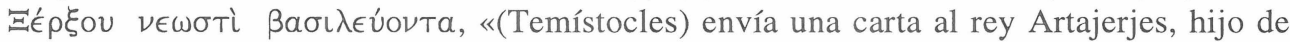
Jerjes, que reinaba desde hacía poco» (HARTMANN 1919:32). El participio mantiene el valor propio del tema, frente a un hipotético aoristo $\nu \in \omega \sigma \tau i ~ \beta a \sigma \iota \lambda \epsilon \cup ́ \sigma \alpha \nu \tau \alpha$, que vendría a querer decir «... que había subido al trono recientemente» ${ }^{3}$.

$\operatorname{ADRADOS}^{4}$ (1992:389 ss.) ha retomado recientemente la cuestión, explicando todos los usos del tema de aoristo a partir de un único valor general: la expresión de la acción completada o acción con su término, sin consideración de su duración. Sostiene que los usos complexivo, puntual e ingresivo son interpretaciones del valor general, que es el perfectivo (ADRADOS 1992:396). Encuentra, sin embargo, que el ingresivo es más difícil de unificar bajo la calificación de perfectivo, pues en el ingresivo la perfección de la acción consiste en

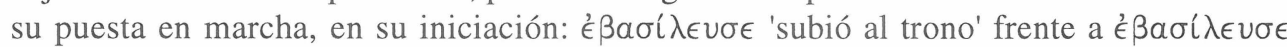
'reinó' (ADRADOS 1992:492). Implicaría una concepción diferente de lo que es el «término» de una acción (ADRADOS 1992:431). Por ello, es encajonado a veces como un uso especial, el más destacado de los especiales (ADRADOS 1992:434). No queda claro, en definitiva, si el aoristo ingresivo es un valor especial o una variante del perfectivo. La unificación de los valores del aoristo descansa sobre la ambigüedad de la definición: el aoristo expresa el contenido verbal con su término. Mas unas veces se opera con el término inicial y otras con el término final. Y es que ADRADOS se desvía de la tradición citada al entender que el ingresivo indica la puesta en marcha de la acción y no la culminación de la acción que pone en marcha un estado, interpretación sensiblemente distinta.

La explicación del valor ingresivo sobre la base de un doble valor de la forma de aoristo fue desarrollada con notable éxito por parte de RUIPEREZ ${ }^{5}$ en lo que respecta al verbo griego antiguo. RUIPÉREZ distingue dos tipos significativos básicos en los lexemas verbales: 1 . $^{\circ}$ Semantemas transformativos son aquellos que expresan una transformación, una modificación del estado. 2..$^{\circ}$ Semantemas no-transformativos son aquellos cuyo significado excluye toda idea de modificación tanto en el sujeto como en el objeto (RUIPEREZ 1954:53). RUIPEREZ llega a la conclusión de que en los semantemas no-transformativos hay dos aoristos, que identifica como valores morfemáticos distintos. La unión de estos dos valores en una sola forma verbal se explica recurriendo a la noción de marca y la estructura privativa de la oposición entre los temas de presente y aoristo, que decansaría en la noción de duración: presente + durativo / aoristo -durativo. El aoristo complexivo, que designa el hecho verbal de principio a fin es descrito como realización del valor neutro. El aoristo

\footnotetext{
${ }^{3}$ Respecto al sentido del adverbio temporal, léase el comentario de CLASSEN al citado pasaje.

4 AdRAdOS, F.R. (1992), Nueva Sintaxis del Griego Antiguo, Madrid, Gredos, 1992, pp. 389 ss.

5 RUIPEREZ M.S. (1954), Estructura y función del sistema de tiempos y aspectos del verbo griego antiguo, Salamanca, P.U.S., 1954.
} 
ingresivo, que designa el inicio del hecho verbal, es descrito como realización del valor negativo: valor puntual. A esta tesis puede hacerse la siguiente objeción de carácter general. El esquema asimétrico que atribuye un valor positivo a un término y dos valores, negativo y neutro al otro término, está construido sobre una categoría minoritaria de verbos, precisamente aquellos que tienen aoristo ingresivo y sólo se realiza completo en esa categoría. Como el propio RUIPEREZ reconoce a lo largo de su estudio, en los verbos con semantema momentáneo y con semantema no-momentáneo transformativo, el valor del aoristo es mucho más constante y es muy difícil, cuando no imposible, identificar un valor neutro distinto del negativo.

El problema que plantean las formas de aoristo "ingresivo" es que aparentemente reflejan dos hechos distintos, en aquellos pocos casos en que este aoristo se combina con un lexema verbal: por una parte el morfema de aoristo tiene dos valores diferenciados, uno complexivo y otro ingresivo; por otra parte el lexema tiene dos sentidos denotativos diferenciados, uno de estado y otro de proceso o acción que desemboca en el estado. Aparentemente al menos, el morfema tiene un valor gramatical complejo y el lexema tiene un valor léxico complejo. La cuestión que se plantea es si una de estas dualidades incide sobre la otra, de suerte que aquella sería mero producto de la combinación con ésta, o bien si ambas son igualmente pertinentes. Debe plantearse así mismo en qué medida un mero producto de la combinación es o no es pertinente.

Antes de proceder al análisis de los morfemas conviene hacer aún unas matizaciones respecto a los lexemas. Pues una descripción de los valores de un tema aspectual con pretensiones de sistematicidad requiere la clasificación previa de los lexemas verbales de los que los temas aspectuales son formados. Desde hace tiempo se viene haciendo una clasificación de los lexemas en dos tipos -al menos- bien diferenciados, conocidos con diversos nombres: transformativos / no transformativos, télicos / atélicos, etc ${ }^{6}$. Hace ya tiempo que BELLO 7 propuso dividir los verbos en desinentes y permanentes, constituyendo un antecedente evidente de las divisiones actuales:

Nótese que en unos verbos el atributo, por el hecho de haber llegado a su perfección, expira, y en otros, sin embargo, subsiste durando: a los primeros llamo desinentes, y los segundos permanentes. Nacer, morir, son verbos desinentes, porque luego que uno nace o muere, deja de nacer o de morir; pero ser, ver, oír, son verbos permanentes, porque sin embargo de que la existencia, la visión o la audición sea desde el principio perfecta, puede seguir durando gran tiempo (BELLO 1988:433).

\footnotetext{
6 Pueden contrastarse definiciones recientes en COMRIE (1976), Aspect, Cambridge, C.U.P, 1976, p. 44; DIK, S.C. (1989), The theory of functional grammar I, Dordrecht, Foris, 1989, p. 92; FANNING, B.M. (1990), Verbal Aspect in New Testament Greek, Oxford, O.U.P., 1990, p.141 ss. Una variante de interés se halla en RIJKSBARON, A. (1989), Aristotle, Verb Meaning and Functional Grammar: Towards a new typology of states of affairs, Amsterdam, Gieben, 1989.

7 Bello, A. (1988) Gramática de la lengua castellana: Destinada al uso de los americanos. Con las Notas de R.J. Cuervo. Edición de R. Trujillo. Madrid, Arco Libros, 1988.
} 
Pero pasemos al análisis de la cuestión. Parto de la hipótesis de que el aoristo es confectivo e indica el contenido verbal acabado. En primer lugar, porque es la hipótesis más avalada por la tradición, incluida la antigua ${ }^{8}$. En segundo lugar, por ser la hipótesis en que deriva el análisis de la oposición presente / aoristo allí donde ambos temas se realizan en un lexema con valor denotativo constante. En tercer lugar, porque no veo razones para desestimarla si se revela capaz de dar razón del uso ingresivo de algunos aoristos.

En principio, pues, el aoristo es confectivo, en tanto no se demuestre lo contrario. Pero este morfema no es utilizable por sí mismo, si no es en combinación con un lexema verbal. Y necesariamente debe desarrollar al menos dos sentidos secundarios, dos realizaciones distintas en los dos tipos distintos de lexemas verbales aludidos antes. El valor confectivo implica el final del contenido verbal. En un lexema permanente, el final no es más que el cese de la actividad o el estado. En un lexema desinente, el final es el momento en que la acción o el proceso es perfecto. En el primer caso, de lexema permanente, el aoristo se realizará como simplemente finitivo, indicando el fin de la actividad o el estado. Pero, dado que en las actividades y estados el fin no tiene mayor trascendencia, no atrae mayor atención que el resto del proceso, el aoristo tenderá a señalar el contenido verbal como un todo completo. De ahí deriva el hecho de que el aoristo se perciba en estos verbos como una forma neutra, sin un valor aspectual específico o bien como una forma complexiva, que

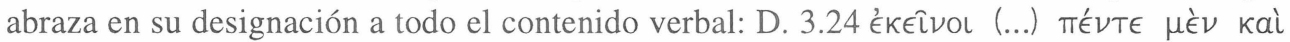

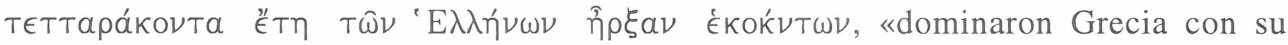
consentimiento durante cuarenta y cinco años». En el segundo caso, de lexema desinente, el aoristo se realizará como expresión de la perfección de la acción o el proceso verbal. La fase final, el momento en que la acción o el proceso alcanza la perfección y cesa de existir, es señalado con especial atención sobre las fases previas, pues tiene mayor relevancia. Ahora tenderá a percibirse como una forma con valor aspectual más marcado, pues resalta una fase

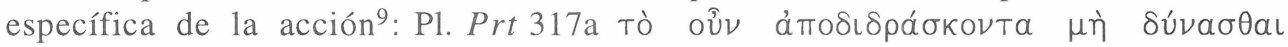

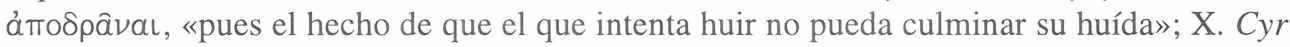

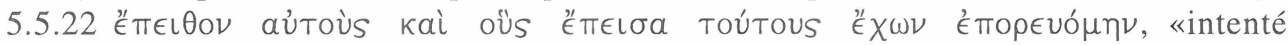
persuadirlos y me puse en camino con aquellos a quienes logré persuadir». La relación entre estos usos se puede reflejar en una proporción, que equipara el perfectivo al finitivo: perfectivo : desinente $::$ finitivo : permanente. En tanto que realizaciones de un valor confectivo general, el perfectivo es al lexema desinente lo que el finitivo o complexivo es al lexema permanente.

Cabe desdeñar estos sentidos como meras implicaciones contextuales, no relevantes en el sistema de la lengua. Pero este desdén derivaría en una visión miope de la realidad lingüística. Veamos por qué. El valor confectivo deriva de la oposición en paradigma de los

\footnotetext{
8 Cf. Martinez VAzQuez, R. "Aspecto verbal en Apolonio Díscolo: el tema de aoristo", Actas del VII Congreso Español de Estudios Clásicos, Madrid, 1989 (1987).

${ }^{9}$ RUIPEREZ 1954:82 encuentra grandes dificultades para encontrar en estos lexemas un aoristo neutro. Da una serie de ejemplos de los que comenta: Es probable que la mayoría de los ejemplos sean aoristos neutros, pero al mismo tiempo resalta en ellos la noción del término final del semantema.
} 
temas aspectuales de aoristo (confectivo) y presente (infectivo). Los valores perfectivo y finitivo derivan de la combinación del valor confectivo con los valores desinente o permanente del lexema verbal en el nivel de la palabra, de la predicación, del discurso, esto es, en los niveles operativos de la lengua, pues en ellos se encuentran las unidades mediante las cuales los interlocutores se comunican entre sí. Dado que el morfema no se emplea por sí solo para comunicar algo, esto es, no es una unidad funcional y, en consecuencia, no tiene otra razón de ser que su realización en unidades funcionales, a su valor se llega por abstracción a partir de tales unidades. No hay motivo para no considerar prioritarias estas unidades y restar relevancia a los elementos que las componen, a sus valores. La perspectiva inversa, de concreción del valor abstracto del morfema en el valor más concreto de la unidad lexema-morfema, puede resultar prioritaria para la descripción y enseñanza de las lenguas o para la explicación de fenómenos dados, pero no tiene por qué imponerse a la inducción en la investigación lingüística. Por ello, a la hipótesis de que todo significado gramatical de un morfema sólo es relevante si se expresa en una oposición paradigmática prefiero la hipótesis de que todo significado que se exprese mediante una forma concreta es relevante independientemente del nivel en que se realice ésa su expresión: la expresión del valor perfectivo está en la combinación de aoristo con lexema desinente. Y es que la primera hipótesis no es correcta, además, porque encadena el concepto de relevancia a un nivel concreto de la expresión, el nivel del paradigma morfológico, desdeñando el nivel del significado. La expresión es sólo un medio que persigue un fin, su significado. Se puede negar relevancia a la diferencia entre medios que persiguen un mismo fin, pero no tiene sentido negar relevancia a un fin por el hecho de que se escatimen medios en su consecución. El concepto de alomorfo no es paralelo al de realización contextual, porque aquél no incide en la comunicación y ésta sí. Es más, la comunicación se construye sobre "realizaciones contextuales". Una gramática independiente de la comunicación no tiene utilidad o sólo la tiene en el plano teórico.

En principio, pues, de acuerdo con la hipótesis expuesta, el aoristo tiende a desarrollar dos sentidos: uno meramente finitivo y otro perfectivo. Ambos expresan el acabamiento del contenido verbal, pero el segundo insiste en su perfección. Ahora bien, a medida que estos sentidos se van consolidando surge la posibilidad de extender su realización a nuevos contextos: de ampliar su ámbito. La tendencia general es que este fenómeno redunde en perjuicio de alguno de los elementos implicados, cuyo sentido se diluye o se modifica en algún aspecto ${ }^{10}$. Y así sucede. Para que el aoristo perfectivo pueda extenderse a los lexemas permanentes, tiene que haber un proceso de adaptación que afecte al morfema o al lexema o a ambos a la vez. El aoristo perfectivo sólo puede realizarse en estos lexemas señalando el inicio del estado o la actividad y así es como se realiza el aoristo ingresivo: señala que el contenido verbal llega a ser perfecto, distanciándose del valor finitivo que el morfema tiene en otros contextos. Mas el valor perfectivo sigue siendo perceptible en los lexemas

10 Doy una variante del principio de relación mutua entre ámbito y contenido formulado por KURYLOWICZ, que dice así: the increase of the range of a given category entails the impoverishment of its content, and vice versa. ("The Evolution of Grammatical Categories", en Esquisses linguistiques II, München, Fink, 1975, p. 41). 
permenentes en que este aoristo se realiza: pues el inicio de un estado es la conclusión de un proceso o una acción previa que lo desencadena. Así en Hdt. 1.12.2 каi ảmoктє́́ vas

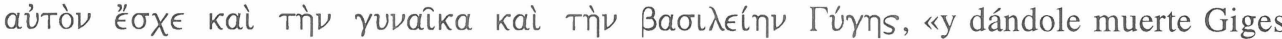
se apoderó de su mujer y su reino», el aoristo insiste en la consecución de la acción que desencadena el estado de posesión del mismo modo que el aoristo en 5.5.22), citado arriba, insiste en el éxito de la persuasión. El paralelismo de estas formas, por su valor perfectivo, se percibe con nitidez en algunos empleos del participio. Como es bien sabido, el valor perfectivo (y el confectivo en general) tiende a derivar en valor de anterioridad en los participios empleados en determinadas construcciones ${ }^{11}$. Así, *té́ $\sigma a s$ aủToús ... significará "tras persuadirlos", "luego de persuadirlos" en esas construcciones.

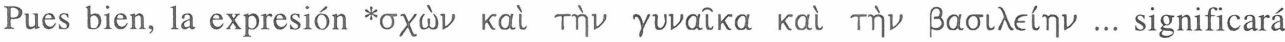
igualmente, en virtud de su valor perfectivo derivado en valor de anterioridad, "tras apoderarse de la esposa y el reino...", "luego de apoderarse de ...". Si su valor consistiera en indicar meramente el inicio de la posesión vendría a significar algo así como *"al apoderarse

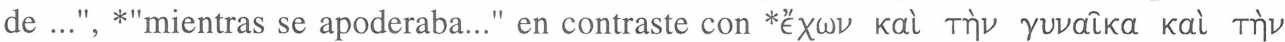

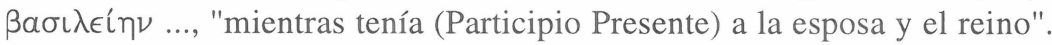

Nótese, por otra parte, que la diferencia entre el aoristo "normal" (complexivo) y el

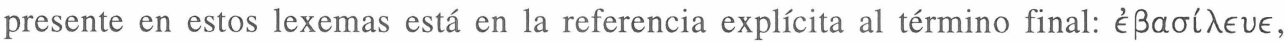

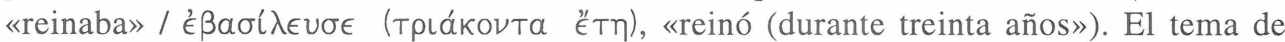
presente refiere el contenido verbal abierto, sin haber alcanzado un término final. El aoristo refiere el contenido verbal completo, todo él, incluido el término final ya alcanzado. El supuesto valor neutro que se ha querido percibir en estos aoristos deriva del hecho de que refieren el hecho verbal completo, pero no de su conmutación con el presente, que apunta al término final como noción relevante. Por su parte, al aoristo ingresivo é $\beta a \sigma i ́ \lambda \epsilon \cup \sigma \epsilon$ "subió al trono", desarrollo secundario, le falta un imperfecto con sentido desinente "subía al trono", "llegaba a ser rey" que se le oponga. Su sentido se alcanza por extensión, más no por oposición paradigmática. De ahí que el valor ingresivo no esté dotado de un morfema específico que lo exprese.

En vista de que el valor perfectivo permanece inalterado en los aoristos ingresivos, esto es, tras su extensión a los lexemas permanentes, es claro que la extensión ha sido posible gracias a que el lexema permanente ha cedido en su sentido, tornándose desinente. Esta formulación se apoya en la apreciación, cada vez más extendida, de que el aoristo ingresivo implica un cambio en el sentido denotativo del verbo. En el aoristo ingresivo de un verbo de estado, el estado es referido sólo implícitamente ${ }^{12}$, porque explícitamente se refiere el proceso previo (SCHWYZER 1950:261). En otros términos, la diferencia entre aor.

11 Cf. KURYLowiCZ, J., The Inflectional Categories of Indo-European, Heidelberg, Carl Winter, 1964, p. 90; HETTRICH, H., Kontext und Aspekt in der altgriechischen Prosa Herodots, Göttingen, Vandenhoeck \& Ruprecht, 1976, pp. 71 ss.

12 RiJksbaron, A. (1984), The syntax and Semantics of the Verb in Classical Greek, Amsterdam, Gieben, 1984, pp. 20-21. 


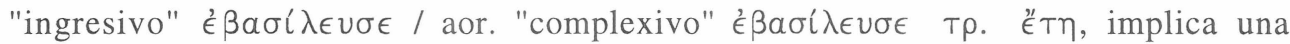
oposición entre un valor transformativo y otro no-transformativo (RUIPEREZ 1954:77).

Esta extensión se puede representar mediante una segunda proporción: perfectivo : desinente $::$ ingresivo: desinente < permanente. La extensión analógica del aoristo perfectivo a los lexemas permanentes provoca una recategorización del lexema ${ }^{13}$. El aoristo ingresivo se caracteriza, frente al perfectivo, por su realización en lexemas con un sentido desinente específico ligado a uno permanente más general.

Dos hechos avalan esta interpretación. 1) Que el caso del aoristo ingresivo es caso particular de un fenómeno más general, que, cuando menos, da lugar a otro fenómeno particular, el caso inverso: extensión del aoristo finitivo a lexemas desinentes, que a tal fin

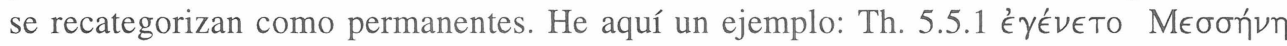

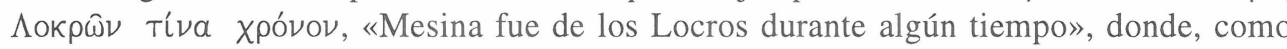

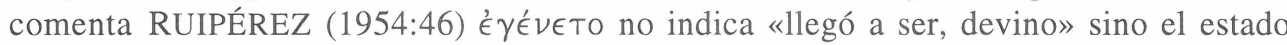

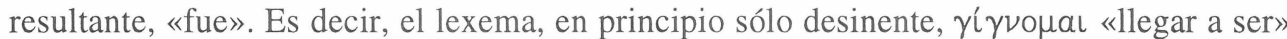
ha desarrollado un semantema permanente «ser», en que el aoristo se realiza como finitivo. RUIPEREZ pretende explicar este ejemplo como uso neutro de aoristo por perfecto. Es difícil estar de acuerdo. Este ejemplo es un reflejo del hecho cada vez más patente de que el lexema verbal tiene un contenido poco constante. 2) El fenómeno de la recategorización de un lexema a fin de combinarlo con una categoría semántica con la que, en principio, sería incompatible, se constata en otras categorías gramaticales distintas del aspecto. Por ejemplo, en el número gramatical. En principio es incompatible con el nombre propio y el nombre no numerativo, a menos que el propio se torne común y el no numerativo se torne numerativo: «No tienen número plural, los nombres proprios de los ombres, como Pedro, Juan, Juana, María; pero si dezimos los Pedros, los Juanes, las Juanas, Las Marías, ia no

\footnotetext{
13 La formulación contraria, de que el morfema cede en su sentido y adquiere un segundo valor, irreductible con el primero, se defiende desde la visión tradicional del lexema como unidad con un valor constante. Ya BELLO explicaba estos usos en castellano como un significado especial del pretérito, no del verbo: El pretérito de los verbos desinentes significa siempre la anterioridad de toda la duración del atributo al acto de la palabra, como se ve por estos ejemplos: «Se edificó una casa»; «La nave fondeó a las tres de la tarde». Mas en los verbos permanentes sucede a veces que el atributo ha llegado a su perfección: «Dijo Dios, sea la luz, y la luz fue»; fue vale lo mismo que principió a tener una existencia perfecta. Es frecuente en castellano este significado del pretérito de los verbos permanentes, precediéndoles las expresiones luego que, apenas, y otras de valor semejante. «Luego que se edificó la casa me mudé a ella»: el último instante de la edificación precedió al primero de la mudanza, porque el verbo edificar es desinente. «Luego que vimos la costa nos dirijimos a ella»: no todo el tiempo en que estuvimos viendo la costa, sino sólo el primer momento de verla, se supone haber precedido a la acción de dirigirnos a ella; porque la acción de ver es de aquellas que, perfectas, continúan durando. (BELLO 1988:433). Puede objetarse que en la luz fue no es el pretérito quien tiene un sentido especial, sino que se está empleando el verbo ser con el sentido pregnante de «llegar a ser». Al fin y al cabo, sea la luz puede así mismo parafrasearse como principie a tener una existencia perfecta. Con todo, esta explicación es implícitamente admitida por todos aquellos que no aluden a un cambio en el sentido del lexema verbal o quienes, como ADRADOS en nuestros días, reconocen en el ingresivo una concepción especial o diferente de lo que es el «término» de una acción (ADRADOS 1992:431), esto es, una concepción diferente del valor morfemático del aoristo, no del valor léxico del verbo.
} 
son proprios, sino comunes» ${ }^{14}$. Sobre el número en los abstractos griegos destaca LASSO ${ }^{15}$ cómo el profuso empleo del plural motivó el paso a concretos de abstractos que, primitivas

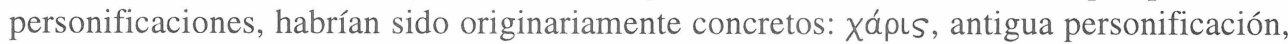
originó un abstracto $\chi a ́ \rho \iota S ~ « g r a c i a, ~ b e l l e z a », ~ « g r a t i t u d » ;$ de éste, el plural $\chi \alpha ́ \rho \iota t \epsilon S$ «muestras o manifestaciones de gratitud», que implica una conversión del abstracto en

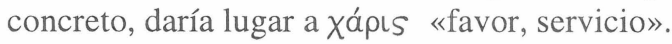

Desde una perspectiva teórica hay varias formulaciones posibles del fenómeno, aunque todas vienen a dar en el mismo camino: el lexema verbal no tiene un sentido denotativo constante. Unas veces se hace ver que los lexemas son recategorizables, pueden cambiar de sentido en circunstancias dadas ${ }^{16}$. Otras veces se renuncia a operar directamente con el lexema verbal, insistiendo en el hecho de que lo que tradicionalmente se considera contenido verbal, en realidad es designado por la predicación, es decir, por el verbo juntamente con sus argumentos (COMRIE 1976). Una postura intermedia, adoptada por RUIPEREZ, consiste en establecer que en el lexema pueden coexistir bajo una misma forma distintas unidades significativas denominadas semantemas. Ya no se asume un valor constante para cada verbo (que sea relevante en el nivel de la denotación), de modo que no es necesario atribuir al morfema aspectual todo cambio de sentido que se observe en el lexema verbal. Se establece que el morfema aspectual se realiza en el semantema, no en el lexema. De modo que, si un verbo presenta una formación aspectual con varios sentidos distintos, no hay necesidad de postular valores distintos en el morfema aspectual, pues la diferencia de sentido puede atribuirse a la existencia de varios semantemas verbales: los sentidos distintos serían realizaciones en semantemas distintos de un único valor morfemático, producto de la combinación del valor del morfema con semantemas diferentes. Véase cómo aplica estos principios en el análisis del valor de perfecto:

El ejemplo de $\beta \epsilon ́ \beta \eta \kappa \alpha$ es ilustrativo por sus tres significados: $1 .^{\circ}$ perfecto

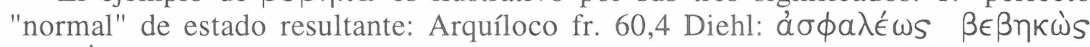

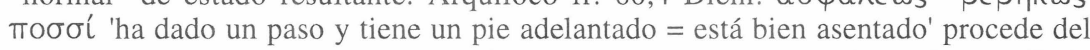
semantema transformativo momentáneo 'dar un paso'. $2 .^{\circ}$ perfecto "normal" de estado resultante: O 90 "Н

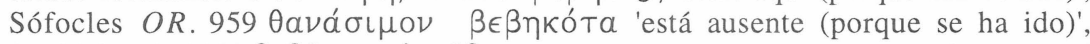

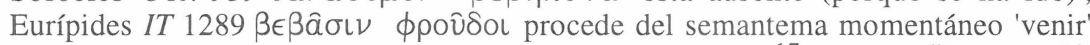
(sin precisar si se viene o se va). $3 .^{\circ}$ perfecto "anómalo"17: Z 495 ả $\lambda \circ \chi_{0}$ os $\delta \dot{~}$

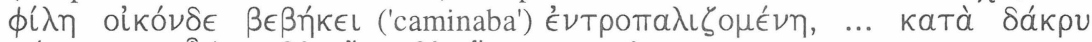

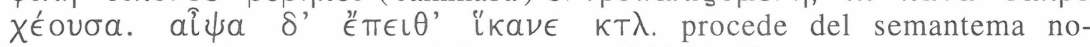
transformativo 'dar pasos, andar'. (RUIPEREZ 1854:54-55).

De acuerdo con estos principios mi hipótesis anterior podría reformularse en los términos siguientes: junto al semantema permanente («reinar») el lexema $\beta a \sigma \iota \lambda \epsilon u ́ \omega$ habría

\footnotetext{
14 Antonio De NeBriJa, Gramática de la lengua castellana, ed. QUILIS, Madrid, Ediciones de Cultura Hipánica, 1992, pp. 107). Para el griego antiguo, cf. LASSO Sintaxis Griega I, Madrid, 1968, 247.

${ }^{15}$ LASSO DE LA VEGA, J.S., Sintaxis Griega I, Madrid, Gredos, 1968, p. 251.

${ }^{16}$ LYONS, J., Introducción en la linguiústica teórica, Barcelona, Teide,

17 Recuérdese que en opinión de RUIPEREZ todos los perfectos proceden de un mismo valor de lengua.
} 
generado un semantema desinente («subir al trono») para dar lugar a las formas de aoristo ingresivo. El lexema $\beta a \sigma \iota \lambda \epsilon u ́ \omega$ tiene, pues, dos semantemas: uno permanente «ser rey» y otro desinente «subir al trono», producto de un desarrollo específico y secundario a partir del anterior. Mas el aoristo ingresivo sería, en definitiva, la realización como perfectivo del valor básico del aoristo en el semantema desinente: $\epsilon^{\prime} \beta a \sigma^{\prime} \lambda \epsilon \cup \sigma \epsilon$ «subió al trono». El aoristo complexivo sería la realización como finitivo del valor básico del aoristo en el semantema permanente: $\dot{\epsilon} \beta a \sigma i ́ \lambda \epsilon \cup \sigma \epsilon$ «reinó» ${ }^{18}$. Este análisis sería coherente con el citado análisis de los perfectos de $\beta a i v \omega$ y también es coherente con el análisis de los valores perfectivo y finitivo del aoristo ${ }^{19}$

La teoría del semantema verbal viene a confirmar la hipótesis expuesta arriba sobre el valor y las realizaciones del morfema gramatical. En fin de cuentas, el semantema es al lexema lo que la realización es al valor del morfema. El semantema es la realización en el contexto del valor del lexema. Al semantema no se llega por oposición entre lexemas, sino a partir de la combinación del lexema con otras unidades funcionales en la predicación, a veces, incluso, con ayuda del contexto de la predicación. Considerados aisladamente, los distintos semantemas de ßaívw no difieren por su expresión, así pues no serían unidades pertinentes, a menos que se aplique la hipótesis anteriormente expuesta. De acuerdo con esta hipótesis los semantemas de un lexema encuentran su expresión en la combinación del lexema con otros términos en la predicación, en el discurso. A diferencia del lexema, cuyo sentido es con frecuencia ambiguo, el sentido referencial (denotativo) de la predicación, con ayuda del contexto, si es preciso, no es ambiguo y se determina en base al compuesto formado por las propiedades semánticas tanto del lexema como de los restantes términos que la componen ${ }^{20}$. Esto es, todos los elementos que constituyen una predicación conforman solidariamente su sentido: el lexema verbal y la determinación del morfema aspectual no son más que una parte del entramado. El sentido permanente o desinente podrá identificarse en los elementos formales y de contenido que distingan las predicaciones que refieren estados de cosas permanentes de las predicaciones que refieren estados de cosas desinentes. En los últimos años se han identificado varios elementos que afectan al carácter permanente o

\footnotetext{
18 Próximo a esta tesis se sitúa FANNING, quien, aún cuando responsabiliza al aoristo ingresivo del cambio de sentido que afecta al verbo, se cuida de definir el valor general del morfema de aoristo al margen de la alteración. Describe el aoristo ingresivo como una variante combinatoria del valor general, que según su opinión, sería el constativo (1990:93).

19 Paradójicamente RUIPEREZ llega a la conclusión contraria y postula que los dos aoristos, complexivo y finitivo (=perfectivo) son reflejos de dos valores distintos del morfema aspectual. Pero este postulado es rechazable por no ser coherente con el propio método establecido. No es coherente con el análisis del perfecto. Si se postula que existen varios semantemas ligados al lexema $\beta a i v \omega$, en distribución perfectamente armónica con los distintos sentidos "contextuales" del tema de perfecto y se constata que el lexema de $\beta a \sigma i \lambda \epsilon u ́ \omega$ muestra diferencias semánticas notables paralelas a los diferentes sentidos del tema de aoristo, lo coherente es postular la existencia de semantemas diversos ligados al lexema de $\beta a \sigma \iota \lambda \epsilon u ́ \omega$. No es coherente sostener que hay un sólo semantema cuyo sentido se ve alterado por obra del morfema aspectual. Y es que tras el postulado de RUIPEREZ late una concepción del lexma verbal como unidad con sentido constante o, cuando menos, con un sentido básico. No se entiende de otro modo la afirmación de que «en el aoristo puede aparecer como transformativo un semantema que en realidad es no-transformativo» (1954:54).

20 CF. DIK 1989:90.
} 
desinente del semantema dentro de la predicación: en el sujeto, en el objeto, en complementos adverbiales, en la negación, en la voz y hasta en el modo (FANNING 1990:48 con abundantes referencias). RUIPEREZ alude a algunos casos, tras definir los semantemas no-transformativos (= permanentes):

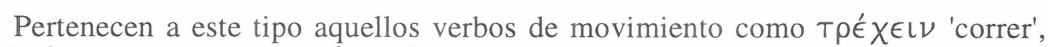

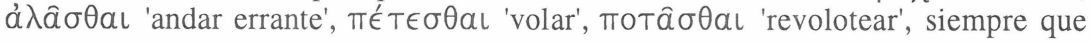
contengan la idea de movimiento pura y simple sin implicar un traslado. Una formación causativa convierte un semantema no transformativo en transformativo: $\pi \epsilon i \theta \epsilon \sigma \theta a \iota$ 'confiar, creer en' / $\pi \epsilon i \theta \epsilon \iota \nu$ 'persuadir'; $\theta a ́ d \lambda \lambda \epsilon \iota \nu$

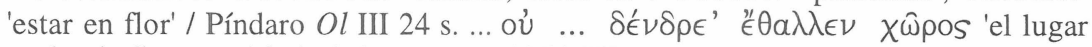
no hacía florecer árboles'. (RUIPEREZ 1954:53).

Esto es, un verbo de movimiento sin determinación en principio tiene semantema permanente, mas si se le añade un complemento que indique el lugar que se cruza, o del cual se parte o al cual se quiere llegar, entonces el verbo tiene semantema desinente, pues tal será el sentido de la predicación correspondiente (cf. FANNING 1990:150). La voz activa (causativa) de $\pi \epsilon i \theta \omega$, la construcción transitiva (causativa) de $\theta a ́ \lambda \lambda \omega$ son asimismo indicios del carácter desinente del hecho referido y, consecuentemente, del semantema en cuestión. El elemento acaso más significativo que distingue dentro de una predicación un semantema desinente de un semantema permanente es el adjunto de duración. Sólo los semantemas permanentes se combinan con el acusativo de duración. En una predicación, pues, con sentido permanente puede haber un acusativo de duración ${ }^{21}$. En una predicación con sentido desinente no puede haber acusativo de duración, sino $̇ \dot{v}+$ dativo ${ }^{22}$. De los ejemplos que siguen, $\gamma i$ ívoua muestra su semantema desinente en el primero y su semantema

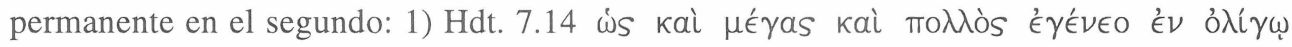

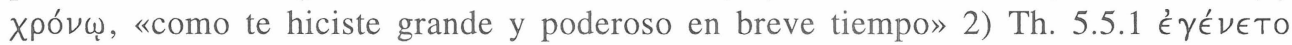

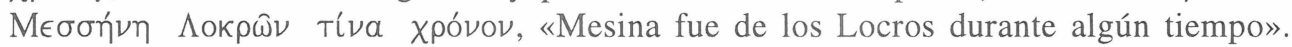
Adviértase que si intercambiamos los adjuntos de duración, el carácter de estas predicaciones

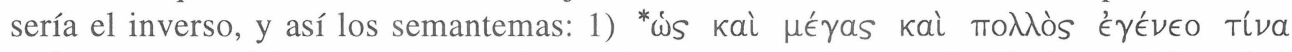

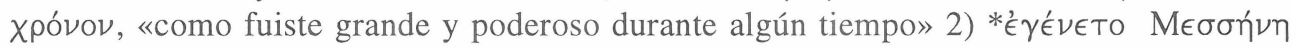

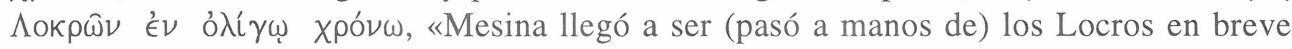
tiempo». Es muy significativo a este respecto el hecho de que se acostumbre ejemplificar el contraste entre aoristo ingresivo y aoristo complexivo añadiendo un acusativo de duración a

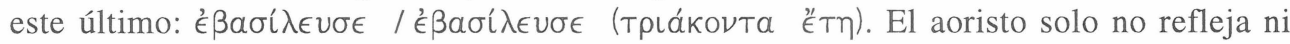
formal ni significativamente ese contraste. Toda predicación construida, entre otros elementos, con el lexema $\beta a \sigma \iota \lambda \epsilon u ́ \omega$ y un acusativo de duración estará formada sobre el semantema permanente «reinar», con independencia del aspecto que la determine.

Otros términos de la predicación pueden desambiguar el sentido del lexema. Así en el ejemplo siguiente, el participio que expresa el medio por el que se realiza la acción, indica que el designatum es la acción que desencadena el estado y no el estado de posesión: Hdt.

21 Esp. durante algún tiempo, ingl. for some time hacen las veces del acusativo de duración en griego.

22 Cf. esp. en poco tiempo, ingl. in (within) some time. 


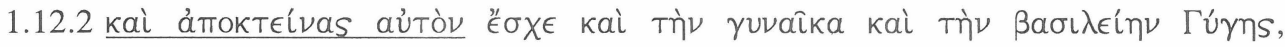
«y dándole muerte Giges se apoderó de su mujer y su reino». El valor del semantema es

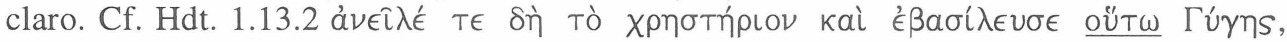
«el oráculo lo ordenó, en efecto, y de este modo Giges devino rey».

Otras veces la predicación es ambigua. Entonces la incertidumbre respecto al valor del semantema se resuelve en el contexto más inmediato. En el ejemplo siguiente évó podría significar «enfermó» o «estuvo enfermo», pero la frase posterior, que alude al

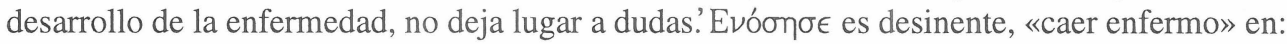

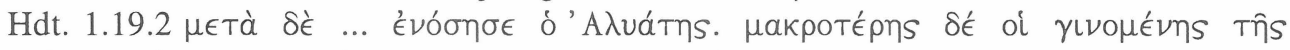
voúбou, «después ... enfermó Aliates. Como su enfermedad se alargaba ...».

Y termino mi análisis. Es el momento de formular la tesis que de él se concluye: el aoristo ingresivo es un subtipo del perfectivo, que a su vez es subtipo del confectivo, único valor general del aoristo. La definición tiene un fondo antiguo, pero aporta una concepción nueva, que supera dificultades de tesis anteriores y constituye la base de la explicación, más que de la clasificación del uso ingresivo del aoristo. El núcleo de la tesis estriba en el hecho de poner en relación y de forma solidaria diferentes elementos procedentes de niveles diferentes: valor general y realización o variante combinatoria por parte del morfema aspectual, lexema y semantema por parte del verbo y la predicación en que el morfema se actualiza. El aoristo ingresivo los implica a todos y no se entiende sin ellos. En tanto que confectivo, como todo aoristo, indica un contenido verbal acabado, cerrado, incluido su término final. Este sentido lo aparta de otros temas aspectuales y lo une a los restantes usos del aoristo. En tanto que perfectivo, se realiza en un semantema desinente y en consecuencia indica la culminación de la acción o el proceso referido. Este sentido lo aparta de los usos meramente finitivos o complexivos y lo une a los perfectivos que se realizan en todo tipo de semantemas desinentes. En tanto que ingresivo, indica la culminación de un proceso o acción que desencadena un estado estrechamente vinculado y esa vinculación lo aparta de los demás perfectivos. Los tres sentidos se ubican en niveles distintos del sistema. El primer sentido, confectivo, en el nivel del contenido de los términos del paradigma morfológico en oposición. Es el único en que sentido y forma morfológica se corresponden. Mas por sí solo explica más bien poco. El segundo sentido, perfectivo, se ubica en el nivel de las realizaciones o variantes combinatorias tanto del morfema como del lexema verbal en la predicación, pues procede de la fusión de ambas. El tercer sentido, ingresivo, se ubica en ese mismo nivel, pero implica uno superior, el del lexema verbal. Pues el lexema vincula el semantema desinente, que refiere la acción o el proceso, al semantema permanente, que refiere el estado subsiguiente.

He basado mi análisis en los mecanismos siguientes, que reflejan el complejo funcionamiento del sistema lingüístico y desearía resumir: 1) Las nociones significativas que se realizan como producto de la combinación entre los términos de las predicaciones no son siempre relevantes en el nivel de las oposiciones paradigmáticas entre morfemas y lexemas, pero constituyen la base sobre la que pivota la comunicación entre interlocutores: 
no pueden ser otra cosa que una parte del sistema lingüístico. 2) La ligazón arbitraria de un significante a un significado, principio sobre el que descansa la concepción moderna de la lengua, no sólo se produce en el nivel de las oposiciones paradigmáticas entre morfemas y lexemas. Tambíen se llega a ella por proporciones y extensiones analógicas, entre otras posibilidades. 3) La ambigüedad e indiferencia de los términos que constituyen oposiciones paradigmáticas se resuelve en los sucesivos niveles en que estos términos se combinan con otros para formar unidades lingüísticas superiores: del morfema a la palabra, de la palabra al sintagma, de éste a la predicación, de ésta al discurso. El sistema ordena, establece leyes en todos los niveles, no sólo en los primeros. 